\title{
Cigarette Flavouring Regulation by Using Aroma-producing Microorganism Isolated from Maotai Daqu
}

\author{
Hui $\mathrm{Li}^{1 *}$, Yang $\mathrm{Qu}^{1}$, Kaiqin Cao ${ }^{1}$, Jianhan Xiong ${ }^{1}$, Keying Hua ${ }^{1}$, Zengyu Liu ${ }^{1}$, Hongfei Wang ${ }^{1}$, Lingfan Yue ${ }^{1}$, Yuan \\ Tang $^{2}$, Gensheng Ding ${ }^{3}$ \\ ${ }^{1}$ Department of Environmental Engineering and Chemistry, Luoyang Institute of Science and Technology, Luoyang 471023, China \\ ${ }^{2}$ State Key Laboratory of Environmental Geochemistry, Institute of Geochemistry, University of Chinese Academy of Sciences, Guiyang \\ 550002, China \\ ${ }^{3}$ Technology Center, China Tobacco Guizhou Industrial Co., Ltd.
}

\begin{abstract}
The selected Moutai aromatic microorganisms and their metabolites were applied into the fermentation of tobacco leaves in order to improve the tobacco quality. The results showed that a variety of aromatic substances in Moutai, as well as the typical flavor substances commonly used in cigarettes, were detected in the fermented tobacco leaf extract. In view of the GC-MS results as well as the sensory smoking evaluation of tobacco leaf extracts under designed experimental conditions, the optimal parameters of stable single-strain fermentation process was at $40{ }^{\circ} \mathrm{C}$ for 10-15 days. The results of specific effects of different fermentation conditions on the content of aroma substances in different parts of tobacco leaves after fermentation, as well as the subsequent sensory evaluation, provided basic data for the improvement of tobacco fermentation and aroma flavoring technology, which was conducive to the development of new cigarettes.
\end{abstract}

\section{Introduction}

Tobacco is an important economic crop with high economic benefits. The internal quality of tobacco leaves, especially the tobacco aroma, is an important subject in tobacco industry. Aroma is an important factor to evaluate tobacco quality and also the core content of tobacco quality. The aroma produced in the process of burning and inhaling of the high quality tobacco is large quantity, pure quality, and mellow taste. There are many research reports on tobacco aroma [1]. At present, the measures to improve the aroma of tobacco mainly include variety improvement, improvement of cultivation measures, improvement of tobacco leaf mixing technology and addition of spices. In the 1990s, with the rapid development of microbial engineering technology, tobacco researchers gradually realized that the use of microbial fermentation tobacco leaves to produce aroma substances has a broad application prospect, and a lot of exploration has been made. Some existing studies have shown that using microbial fermentation of tobacco leaves can greatly shorten the fermentation time, improve the internal quality of tobacco leaves, increase the color and luster, reduce the pungent smell of tobacco leaves, remove bitter, green and mixed smell, adjust the pungent taste caused by high nitrogen content, and give tobacco leaves natural mellow and full aroma [2].

The existing research on tobacco aroma enhancement using microbial fermentation and fermentation extracts and other biotechnological means mainly focuses on the microbial species isolated from tobacco [3], and there are few reports on introducing microorganisms and their metabolites into other media. The purpose of this study was to link the function development of Moutai aromatic microorganisms with the improvement of tobacco quality, and to apply the selected Moutai aromatic microorganisms and their metabolites to the fermentation of tobacco leaves to improve the aroma quality of tobacco leaves and cigarettes. This technology is environmentally friendly, with unique flavor of Chinese wine, and is an innovative research idea.

Environmental conditions not only affect the growth of microorganisms, but also have an important effect on the their metabolites. Moutai is very popular because of its unique aroma. The aroma of Moutai comes from the microbial fermentation products in the unique region, Therefore, it is of great significance to apply the aromaproducing strain isolated from Maotai Daqu to the tobacco fermentation and flavoring, to improve the existing tobacco fermentation technology and to develop tobacco products with unique style.

Maotai and its Daqu have a lot of flavor substances which do not exist in tobacco leaves and these ingredients are the important aromatic substances of Maotai liquor, these key flavoring substances in Moutai are produced by microbial fermentation [4]. The same microbial groups in tobacco and Maotai liquor mainly include Bacillus sp. (Bacillus licheniformis, Bacillus subtilis, Bacillus coagulans) and Aspergillus sp.

* Corresponding author. E-mail address: orient.lihui@163.com 
(Monascus, Paecilomyces). It has been reported that the metabolites of Bacillus licheniformis are mostly flavor substances and flavor precursors, which are important components of flavor substances in Maotai liquor. The main metabolites of Bacillus subtilis are the important flavor components in Maotai liquor. At the same time, these microflora also play the role of aroma production in tobacco fermentation. Therefore, it is reasonable to speculate that some of the aromatic microorganisms in Maotai Daqu have important significance for improving the aroma quality of tobacco leaves and cigarettes. In other words, the introduction of maotai aromatic microorganism can increase the variety of high-quality microorganism in tobacco fermentation, and these highquality microorganism combinations have an impact on tobacco fermentation, forming some flavor substances similar to wine fragrance and improving the quality of tobacco leaves.

In conclusion, the aromatic microorganism of Maotai liquor can increase the species of high-quality microorganism in tobacco fermentation, and these highquality microorganism combinations can form some aroma substances similar to wine fragrance and improve the quality of tobacco leaves.It is beneficial to make tobacco leaf fermentation with maotai aroma microorganism.

\section{Material and methods}

\subsection{Medium}

PDA medium was used as the isolation medium, that is, take $200 \mathrm{~g}$ potato, chopped peeled wash, add $1000 \mathrm{ml}$ $\mathrm{ddH}_{2} \mathrm{O}$ to boil for 30 minutes. Four layers of gauze filtration, $20 \mathrm{~g}$ glucose and 15-20 g Agar were added, fully dissolved and sterilized at $121^{\circ} \mathrm{C}$ for $30 \mathrm{~min}$.

\subsection{Bacterial species}

After cultured in PDA medium at $37{ }^{\circ} \mathrm{C}$ for $24 \mathrm{~h}$, the Mixed bacteria liquid of Bacillus subtilis and three dominant aroma-producing strains (Bacillus subtilis, Bacillus licheniformis and Bacillus amylase) which were isolated from Maotai Daqu was collected and mixed with the same amount.

\subsection{Fermentation process}

Two kinds of bacterial liquid (single bacterial liquid of Bacillus subtilis and the mixed bacterial liquid of three strains) were sprayed on the different parts of tobacco leaves (upper tobacco, middle tobacco and lower tobacco) by $1 \%$ ( $1 \mathrm{~mL}$ bacterial liquid per kilogram of tobacco leaves). Fermentation pits with different temperatures were placed for fermentation $\left(30{ }^{\circ} \mathrm{C}, 40{ }^{\circ} \mathrm{C}, 50{ }^{\circ} \mathrm{C}\right)$; Samples were taken at different fermentation time $(10 \mathrm{~d}$, $15 \mathrm{~d}, 20 \mathrm{~d}, 25 \mathrm{~d}$ ), and fermentation products were extracted from tobacco samples after different fermentation treatments by simultaneous distillation, and the components of flavor substances were analyzed by GC-MS.

\subsection{Extraction and treatment of aromatic substances}

Simultaneous Distillation Extraction, SDE, Sample pretreatment: After pulverization, weigh $25 \mathrm{~g}$ of the pulverized tobacco sample for 40 mesh in a $1000 \mathrm{~mL}$ flat-bottomed flask, add $350 \mathrm{~mL}$ saturated salt water, add $1000 \mu \mathrm{L}$ ethanol solution containing $1.0 \mathrm{mg} / \mathrm{mL}$ phenyl propionate, and add two zeolites, add $40 \mathrm{~mL}$ dichloromethane into a $100 \mathrm{~mL}$ flat-bottomed flask. At the same time, one end of the distillation and extraction device is connected with a $1000 \mathrm{ml}$ flat-bottomed flask containing $25 \mathrm{~g}$ of tobacco dust and $350 \mathrm{ml}$ of saturated salt water. The electric heating sleeve with controllable voltage is used for heating. The other end is connected to a $100 \mathrm{~mL}$ flat-bottomed flask containing $40 \mathrm{~mL}$ dichloromethane and heated in a water bath. The temperature of the water bath was kept at $60{ }^{\circ} \mathrm{C}$. After the dichloromethane began to reflux, the voltage of the electric heating jacket was adjusted to control the distillation speed between the water phase and the organic phase at 1:0.85-1, the distillation was extracted for 2 hours. The extract was washed twice with 5\% hydrochloric acid and 5\% sodium hydroxide solution respectively. Anhydrous sodium sulfate dried at $500{ }^{\circ} \mathrm{C}$ was added to the organic phase and dried overnight. The filtrate was concentrated to about $1 \mathrm{~mL}$ on the rotary evaporator to be measured. Make three parallel for each sample and take the average value.

Chromatographic analysis conditions and qualitative and quantitative analysis methods: The chromatographic conditions were as follows: DB-5MS column, $30 \mathrm{~m} \times$ $0.25 \mathrm{~mm} \times 0.25 \mu \mathrm{m}$, column flow rate was $1.0 \mathrm{~mL} / \mathrm{min}$, temperature was programmed, $40{ }^{\circ} \mathrm{C}$ was maintained for $5 \mathrm{~min}, 5^{\circ} \mathrm{C} / \mathrm{min}$ was increased to $280{ }^{\circ} \mathrm{C}$, maintained for $10 \mathrm{~min}$, sample volume was $1 \mu \mathrm{L}$, split ratio was 30: 1 . Mass spectrum conditions: solvent delay $3 \mathrm{~min}$, transmission line temperature $280{ }^{\circ} \mathrm{C}$, ionization mode: $\mathrm{EI}$, ionization energy $70 \mathrm{eV}$, quadrupole temperature $150{ }^{\circ} \mathrm{C}$, ion source temperature $230{ }^{\circ} \mathrm{C}$, mass spectrum scanning range: $35-550 \mathrm{amu}[5]$.

The content of each identified chromatographic component is given by the relative mass of internal standard, and the calculation formula is as follows:

$\mathrm{Ms}(\mathrm{ug} / \mathrm{g})=(\mathrm{Mi} \times \mathrm{As}) /(\mathrm{Ai} \times \mathrm{M} 0)$

Ms represents the content of aromatic ingredients $(\mu \mathrm{g} / \mathrm{g})$, Mi represents the mass of added internal standard compounds $(\mu \mathrm{g})$, As represents the peak area of aromatic ingredients, $\mathrm{Ai}$ represents the peak area of internal standard compounds, and M0 represents the mass of tobacco sample $(\mathrm{g})$.

\subsection{Bacterial liquid used in tobacco fermentation}

The Bacillus subtilis isolated from Maotai Daqu was used as single bacterial solution and three dominant aroma-producing strains were used as mixed bacterial 
solution. Two kinds of bacterial solution were sprayed on different parts of tobacco leaves to improve the fermentation process of tobacco leaves. The main design idea was as follows: The four factors (bacteria (single bacteria, compound bacteria), temperature $\left(30^{\circ} \mathrm{C}, 40^{\circ} \mathrm{C}\right.$, $\left.50^{\circ} \mathrm{C}\right)$, culture time $(10 \mathrm{~d}, 15 \mathrm{~d}, 20 \mathrm{~d}, 25 \mathrm{~d})$, tobacco leaf variety (upper, middle and lower part)) were combined freely to design the experimental group for spraying experiment, and the control group was set at the same time. A total of 108 experiments were combined.

During the fermentation process, representative samples were selected from 108 boxes of tobacco leaves under different fermentation conditions to determine the extraction of fermentation products by GC-MS. The sample description is listed in Table 1.

\subsection{Smoking evaluation of fermented tobacco leaves after different treatments}

The tobacco leaves fermented under different conditions were evaluated from the aspects of aroma temperament, aroma quantity, taste, gray, delicacy, softness and concentration. Each index was the average value of the evaluation results of 7 cigarette evaluation experts from China Tobacco Group, and the samples were analyzed according to the comprehensive results of several indexes.

\section{Results and discussion}

\subsection{Test results of aroma components of fermented tobacco leaf extract by GC-MS}

The GC-MS test was performed on partially representative fermented tobacco leaves from 108 cartons treated with different bacterial solutions. The results showed that a total of 77 compounds were detected in fermented tobacco. By comparing the aroma components in Moutai liquor reported in literature and the aroma components in cigarettes provided by Guizhou China Tobacco Group, it was found that 18 kinds of aroma components in Moutai liquor and cigarettes appeared in fermented tobacco leaves. The maotai liquor aroma compounds with furfural, palmitic acid, ethyl palmitic acid, the aroma components of tobacco include Benzaldehyde, Benzyl alcohol, Solanone, $\beta$-semarone, $\beta$ dihydrosemarone, Geranyl acetone, $\beta$-violanone, Dihydrokiwifruit lactone, Megastrienone A, Megastrienone B, Megastrienone C, Megastrienone D, Neophytopadiene. In addition, there is a common component $\beta$-phenylethanol.

$\beta$-phenylethanol has elegant, delicate and lasting rose fragrance. It is added in food, daily chemical products and tobacco and has synergistic effect on other aroma components, and it's the iconic substance of the excellent level of the fermented liquor [1]. At present, the most reported microorganisms that can transform into $\beta$-phenylethanol are mainly concentrated in Saccharomyces cerevisiae, Kluyavirus marcus and Kluyavirus sinensis. In this paper, the aroma components with this important characteristic were also produced in tobacco fermentation by using aroma producing bacteria of Maotai Daqu. It can not only bring special wine aroma to tobacco leaves, but also enhance the aroma enhancing effect of other aroma components in tobacco leaves. In addition, solanone, megastigmatrienone, $\beta$ dihydromacarone are the spices often used in cigarette flavoring.

In this paper, the aroma producing bacteria of Maotai Daqu were used in tobacco leaves fermenting to produce the above representative components of tobacco flavor substances that play an important role in tobacco flavor. The fermentation conditions conducive to the production of all kinds of substances will be analyzed according to the changes in the composition content of flavor substances.

A preliminary analysis was made on the fermentation samples with different treatments for 18 kinds of flavor substances composition, the fermentation temperature and time effect of single bacteria and fermentation temperature and time effect of compound bacteria were compared respectively, the effects of strains, fermentation temperature and fermentation time on the content of flavor compounds were compared, the results are listed in Table 1.

Compared with samples 21, 24 and 27, it can be seen that there was no significant increase in the composition of aroma compounds when the middle tobacco leaves fermentation at $40{ }^{\circ} \mathrm{C}$ for 10 days by single and complex strains. Compared with the samples 39, 42 and 45 , it can be seen that the components of aroma substances were basically increased after fermentation at $30{ }^{\circ} \mathrm{C}$ for 15 days by single bacteria and compound bacteria, and the effects were all good. Compared with sample 47, 50 and 53 , it can be seen that when the upper tobacco leaves were fermented at $40{ }^{\circ} \mathrm{C}$ for 15 days, the effect of compound bacteria was better. while some aroma substances did not increase significantly after the fermentation of single bacteria. Compared with the samples 48,51 and 54 , it can be seen that the single bacteria had a better effect when the middle tobacco leaves were fermented at $40{ }^{\circ} \mathrm{C}$ for 15 days, while some flavoring substances did not increase significantly after the fermentation of the compound bacteria. Compared with sample 75, 78 and 81, it can be seen that after 20 days of fermentation with single bacteria at $40^{\circ} \mathrm{C}$, the content of aroma substances is basically higher than that of the control experiment, and the effect of compound bacteria is not as good as that of single bacteria. Compared with sample 102, 105 and 108, the results of single bacteria and compound bacteria fermentation for 25 days at $40{ }^{\circ} \mathrm{C}$ were better than those of the control experiment, and the effect of compound bacteria was better than that of single bacteria, that is, the yield of aromatic substances of the compound bacteria fermentation for 25 days at $40{ }^{\circ} \mathrm{C}$ was better. Compared with sample 42 and No. 51 , fermentation at $40{ }^{\circ} \mathrm{C}$ for 15 $\mathrm{d}$ was better than that at $30^{\circ} \mathrm{C}$ for $15 \mathrm{~d}$. Based on the above comparison results, it can be seen that the content of aroma substances increased significantly when the single bacteria were fermented at $40{ }^{\circ} \mathrm{C}$ for 15 days, and 
this culture condition was more conducive to the production of most aroma substances on the whole.

\subsection{Evaluation results of tobacco leaf after fermentation under different treatments}

A total of 108 tobacco samples with different fermentation treatments were evaluated. The quality of aroma, taste, odor, irritant, energy, burning, gray, delicacy, softness and concentration were quantitatively evaluated. Each index is the average of the evaluation results of 7 cigarette experts in China Tobacco Guizhou Group. Finally, according to the comprehensive results of several indexes, the samples were analyzed from three aspects of effects of different strains, effects of different fermentation temperature and time to select the optimal fermentation treatment scheme. The results showed that the optimal fermentation conditions were different in different parts of tobacco leaves, and the overall trend was that the single bacteria had a better fermentation effect at $40{ }^{\circ} \mathrm{C}$ for $10-15$ days, while the lower tobacco was more suitable for appropriately extending the fermentation time and lowering the fermentation temperature.

Table 1. The GC-MS analysis of the flavor substances in different fermented tobacco samples (count on peak area).

\begin{tabular}{|c|c|c|c|c|c|c|c|c|c|c|c|c|c|c|c|c|c|c|c|c|c|c|c|c|}
\hline Serial number & 21 & 24 & 27 & ${ }^{39}$ & 42 & 45 & 47 & 48 & 49 & ${ }_{s 0}$ & ${ }_{51}$ & 52 & 53 & 54 & 55 & ${ }_{57}$ & 60 & 63 & 75 & 78 & 81 & 102 & 105 & 108 \\
\hline Treatment & $\mathrm{ck}$ & $\mathrm{sB}$ & св & $\mathrm{ck}$ & $\mathrm{SB}$ & св & $\mathrm{ck}$ & $\mathrm{ck}$ & $\mathrm{ck}$ & $\mathrm{SB}$ & $\mathrm{sB}$ & $\mathrm{sB}$ & св & св & св & $\mathrm{ck}$ & $\mathrm{sB}$ & св & $\mathrm{ck}$ & sB & св & $\mathrm{ck}$ & sв & св \\
\hline $\begin{array}{c}\text { The } \\
\text { temperaure } \\
\text { (c) }\end{array}$ & 40 & 40 & 40 & ${ }^{30}$ & ${ }_{30}$ & ${ }_{30}$ & 40 & 40 & 40 & 40 & 40 & 40 & 40 & 40 & 40 & so & so & ${ }_{50}$ & 40 & 40 & 40 & 40 & 40 & 40 \\
\hline $\begin{array}{l}\text { Fermencation } \\
\text { time (d) }\end{array}$ & 10 & 10 & 10 & 15 & 15 & 15 & 15 & 15 & 15 & 15 & 15 & 15 & 15 & 15 & 15 & 15 & 15 & 15 & 20 & 20 & 20 & 25 & 25 & 25 \\
\hline Parts Modules & MP & MP & $\mathrm{MP}$ & MP & MP & MP & uP & $\mathrm{MP}$ & LP & UP & MP & LP & uP & MP & LP & MP & MP & $\mathrm{MP}$ & MP & MP & MP & MP & MP & MP \\
\hline Benzaldechyde & 0.12 & 0.1 & 0.11 & 0.12 & 0.12 & 0.15 & 0.14 & 0.13 & 0.15 & 0.12 & 0.12 & 0.13 & 0.14 & 0.15 & 0.13 & 0.2 & 0.13 & 0.17 & 0.11 & 0.13 & 0.14 & 0.15 & 0.11 & 0.14 \\
\hline 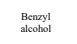 & 2.18 & 1.68 & 1.81 & 1.91 & 2.18 & 2.6 & 2.68 & 2.28 & 1.89 & 2.88 & 2.27 & 1.51 & 1.01 & 1.32 & 0.92 & 1.57 & 1.15 & 1.75 & 1.68 & 1.75 & 1.6 & 1.92 & 1.97 & 2.12 \\
\hline Solanone & 9.84 & 8.47 & 9.11 & 9.24 & 9.66 & 10.99 & 16.55 & 16.86 & 17.18 & 9.36 & 9.95 & 9.97 & 4.17 & 3.9 & 4.24 & 12.08 & 9.41 & 9.25 & 9.9 & 10.2 & 8.95 & 9.53 & 10.5 & 9.71 \\
\hline$\underset{\text { Damascenone }}{\beta-}$ & 4.36 & 3.82 & 4.04 & 3.86 & 4.23 & 4.89 & 5.61 & 5.32 & 5.77 & 5 & 5.19 & 4.87 & 4.25 & 4.51 & 4.31 & 6.92 & 5.49 & 5.91 & 5.34 & 5.27 & 4.78 & 5.09 & 5.3 & 5.82 \\
\hline $\begin{array}{c}\substack{p-\\
\text { Dilytomanar } \\
\text { one }} \\
\text { one }\end{array}$ & 1.28 & 1.1 & 1.18 & 1.1 & 1.2 & 1.42 & 1.79 & 1.63 & 1.82 & 1.56 & 1.59 & 1.48 & 1.38 & 1.51 & 1.42 & 2.47 & 1.91 & 2.17 & 1.67 & 1.62 & 1.5 & 1.62 & 1.71 & 1.95 \\
\hline \begin{tabular}{c} 
Geranylacton \\
\hdashline
\end{tabular} & 1.49 & 1.15 & 1.38 & 1.29 & 1.39 & 1.5 & 1.78 & 1.74 & 1.76 & 1.33 & 1.37 & 1.26 & 1.05 & 1.16 & 1.28 & 1.82 & 1.46 & 1.38 & 1.37 & 1.41 & 1.39 & 1.41 & 1.32 & 1.58 \\
\hline$\beta$-1onone & 0.58 & 0.56 & 0.61 & 0.64 & 0.58 & 0.66 & 0.78 & 0.89 & 0.92 & 0.7 & 0.73 & 0.69 & 0.7 & 0.72 & 0.73 & 0.69 & 0.7 & 0.79 & 0.63 & 0.62 & 0.72 & 0.61 & 0.74 & 0.68 \\
\hline $\begin{array}{l}\text { Dilydroactini } \\
\text { diolidide }\end{array}$ & 0.99 & 0.69 & 0.82 & 0.67 & 0.84 & 1.17 & 1.26 & 1.11 & 1.1 & 1.04 & 1.09 & 0.67 & 0.91 & 1.07 & 0.95 & 1.29 & 0.73 & 1.07 & 1 & 0.93 & 0.9 & 0.87 & 0.91 & 1.15 \\
\hline 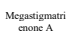 & 1.92 & 1.57 & 1.71 & 1.6 & 1.85 & 1.99 & 2.61 & 2.39 & 2.76 & 2.1 & 2.5 & 2.16 & 2.4 & 2.67 & 2.68 & 3.57 & 2.62 & 3 & 2.63 & 2.49 & 2.09 & 2.02 & 2.19 & 2.83 \\
\hline Megastignatri & 4.72 & 4.28 & 4.39 & 3.87 & 3.93 & 4.7 & 7.4 & 6.87 & 7.52 & 5.34 & 5.28 & 4.98 & 6.64 & 6.8 & 7.01 & 8.81 & 6.4 & 7.12 & 5.71 & 5.74 & 5.46 & 5.77 & 5.79 & 6.56 \\
\hline 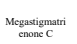 & 1.46 & 1.11 & 1.19 & 1.11 & 1.29 & 1.55 & 1.9 & 1.66 & 1.81 & 1.53 & 1.7 & 1.35 & 1.68 & 2.02 & 1.85 & 2.14 & 1.53 & 1.92 & 1.65 & 1.59 & 1.52 & 1.45 & 1.63 & 1.91 \\
\hline $\begin{array}{c}\text { Megaxtigmatri } \\
\text { enonen D }\end{array}$ & 4.44 & 3.87 & 4.17 & 3.65 & 4 & 4.53 & 7.78 & 7.05 & 7.78 & 5.16 & 5.2 & 5.1 & 5.82 & 6.72 & 6.38 & 8.09 & 6.15 & 6.94 & 5.47 & 5.2 & 5.14 & 5.25 & 5.6 & 6.51 \\
\hline $\begin{array}{l}\text { Nepophysadicen } \\
\mathrm{c}\end{array}$ & 389 & 356 & 332.3 & 419.8 & 496.1 & 471.08 & 405.2 & 405.2 & 370.5 & 493 & 446.8 & 407.07 & 562.4 & $\frac{501 .}{4}$ & 519.6 & 491.7 & 333.7 & 453.62 & 421 & 508 & $\begin{array}{c}365.1 \\
1 \\
1\end{array}$ & 397.2 & 426 & 434.97 \\
\hline Palmitic acid & 28.8 & 18.1 & 16.5 & 16.62 & 20.55 & 33.8 & 21.4 & 18.94 & 22.87 & 34.04 & 31.63 & 14 & 28.56 & $\begin{array}{c}36.9 \\
4\end{array}$ & 34.5 & 50.35 & 19.67 & 49.48 & 35.92 & 36.8 & 31.48 & 34.54 & 35.3 & 40.06 \\
\hline $\begin{array}{c}\text { Ehlyy } \\
\text { Palmitiate }\end{array}$ & 1.16 & 0.92 & 1.06 & 1.21 & 1.36 & 1.36 & 0.98 & 0.96 & 0.75 & 1.39 & 1.31 & 1.19 & 1.04 & 1.04 & 0.9 & 1.32 & 1.06 & 1.52 & 1.42 & 1.36 & 1.16 & 1.21 & 1.28 & 1.39 \\
\hline Furfural & 1.71 & 1.48 & 1.48 & 1.47 & 1.67 & 1.96 & 2.13 & 2.05 & 1.93 & 1.97 & 2.08 & 1.99 & 1.73 & 1.94 & 1.6 & 2.7 & 2.21 & 2.39 & 2.04 & 2.09 & 1.64 & 1.95 & 2.09 & 2.38 \\
\hline phenyldethanol & 1.16 & 1.01 & 0.95 & 1 & 1.12 & 1.29 & 1.68 & 1.46 & 1.3 & 1.48 & 1.19 & 0.88 & 0.69 & 0.84 & 0.6 & 1.34 & 0.85 & 1.33 & 0.97 & 1.04 & 0.9 & 1.07 & 1.15 & 1.3 \\
\hline
\end{tabular}

SB: single bacteria; CB: compound bacteria; LP: lower part; MP: middle part; UP: upper part

\section{Conclusion}

Combined with the analysis of GC-MS and the evaluation results of tobacco leaf extracts after fermentation under different conditions, a better and stable tobacco leaf fermentation process was obtained, that is, single-strain fermentation at $40{ }^{\circ} \mathrm{C}$ for $10-15$ days. Under this fermentation condition, the average aroma increasing effect of the three kinds of tobacco leaves after fermentation was better. There results will provide useful reference for the improvement of cigarette flavoring technology in the future.

\section{Acknowledgement}

Undergraduate Innovation and Entrepreneurship Training Program of China (202011070010). 


\section{References}

1. W.W. WEEK, Recent Advance in Tobacco Science, 11 (1985)

2. H. Li, B. Lian, Annals of Microbiology, 64, (2014)
3. M.M. Etschmann, W. Bluemke, Applied Microbiology Biotechnology, 59, 1 (2002)

4. H. Li, B. Lian, Y. Ding, Annals of Microbiology, 64, $4(2014)$

5. L.Y. Liu, X. Y. Wang, S. Wang, Journal of Separation Science, 4 (2017) 